\title{
Evaluating the impact of different PV control strategies on distribution network operation
}

\author{
Ankur Mishra, Mehdi Farzinfar, Momen Bahadornejad and Nirmal-Kumar C. Nair \\ Department of Electrical and Computer Engineering \\ University of Auckland \\ Auckland, New Zealand
}

\begin{abstract}
For managing carbon emission, micro-generation with different capabilities are being actively explored for grid integration. Such small scale generation connected to low and medium voltage conventional network that are not designed to accommodate distributed generation pose various issues like voltage rise during off peak hours. The aim of this paper is to evaluate different inverter control strategies under different conditions created by pseudo-random events through simulation on a test network. PQ control mode, voltage control mode and voltage droop control mode are compared in terms of node voltage, line losses and impact on fault. Several aspects like load, PV penetration and inverter properties are varied to capture parameters like node voltages and line losses for evaluating impact of PV control modes on the network. The representative network which has been extracted from New Zealand grid data and all assessments are carried out using simulated in DIgSILENT power factory. The main emphasis of this paper is around development of index which can quantify the effect of PV control mode on network parameters.
\end{abstract}

Keywords- photo-voltaic, inverters, distributed generation, distribution network, reactive power control, voltage control, line losses, fault analysis

\section{INTRODUCTION}

Integration of renewable energy resource to high and medium voltage network has been mostly a well established practice now. However, due to easy availability of PhotoVoltaic (PV) inverters, low voltage network in countries like New Zealand is likely to experience increase in the connection of PV generation. Customer's interest to save costs is a likely driver for rapid PV uptake in residential sector. Due to such a demand on the low voltage network, problems due to bidirectional power flow are bound to occur as conventional radial distribution networks are not designed to handle such an operating scenario. This necessitates a comprehensive model for understanding the impacts of large scale domestic PV generation on low voltage distribution network. Several related research has been conducted to enhance the process of understanding impacts of distributed generation. For example in [1], an on-line assessment tool based on variable-width sliding-window is proposed which can accept load data as input to provide impact analysis. This partly bypasses the need of an off-line model. However, the accuracy of such a model depends on measurement of load data, and is limited by the extent to which data is available. This invokes the importance of simulation models, which can be enhanced to provide accurate outcomes pertaining to particular situations. Authors

This research supported financially by the New Zealand Ministry of Business, Innovation and Employment (MBIE) GREEN Grid project funding (2012-18). A. Mishra (amis587@aucklanduni.ac.nz), M. Farzinfar (mfar814@aucklanduni.ac.nz), M. Bahadornejad (m.bahadornejad@ auckland.ac.nz), and N.-K.C. Nair (n.nair@auckland.ac.nz) are with the Power Systems Group of Department of Electrical and Computer Engineering at University of Auckland, Auckland. of [2] describe such a method where impacts of large PV systems on network are drawn through clustering techniques. Similar techniques can be applied to small generation in residential sector as well [3]. Grouping the problem by location is another approach as seen in [4], [5], where the placement of PV in rural areas is seen to be problematic as compared to urban area due to high impedance of distribution line which is considered to be main factor in voltage rise issues. In [6], a more detailed approach is carried out where impacts of domestic PV generation on residential network are directly simulated on a suitable platform. Some impact mitigation techniques are discussed in [7]-[9].

This paper presents a comprehensive framework to capture different parameters of distribution network in case of different penetration of distributed generation. The main parameters under consideration are line voltages and line losses. DIgSILENT power factory is used to create a model and subsequent simulations. The random placement of PV throughout the network with percentage penetration as initial input and carrying out multiple simulations to compare impacts on placement of PV enables user to analyze several scenarios. As penetration levels are changed, changes in voltage, line losses and voltage drop during fault are captured. However, it is to be noted that for comprehensive study, the control strategy of distributed generation must also be considered as mentioned in [10], as reactive power compensation through inverter control can help mitigate impacts of high PV penetration. The model provides flexibility to change the control mode of generators to account for different operating power factors during the assessment of the impacts. Finally, the paper concludes by suggesting an index for voltage regulation which can concisely describe the state of distribution network under various circumstances.

\section{IMPACTS OF PV INTEGRATION AND INVERTER CONTROL ON DISTRIBUTION NETWORK SELECTING A}

In conventional voltage control, it is assumed that there is only one generating unit in the system. But due to integration of distributed renewable energy into the system, this assumption is void. Thus new operating conditions arise and lead to reliability issues like power quality, voltage drop/rise, frequency fluctuations and unreliable protection schemes. On the other hand, there would be advantages like reduced line losses as now generation is close to demand and active power flow from generation source to load is reduced. Some of the 
effects are discussed below with motive of clarifying the effect of high PV integration in distribution network.

\section{A. Voltage deviation}

For a passive network, the voltage drop is consistent along the line due to line losses. The usual practice is to increase the sending side voltage up to $5 \%$ and compensate for reactive power by adding capacitor banks in the system. Considering there is no reactive power compensation, the voltage drop can be calculated as (Fig. 1):

$$
\begin{aligned}
\Delta V & =V_{R}-V_{S}=I(R+j X) \\
& =\frac{\left(P_{\text {Load }} R+Q_{\text {Load }} X\right)+j\left(P_{\text {Load }} X-Q_{\text {Load }} R\right)}{V_{R}^{*}} \\
& \approx \frac{P_{\text {Load }} R+Q_{\text {Load }} X}{V_{R}}
\end{aligned}
$$

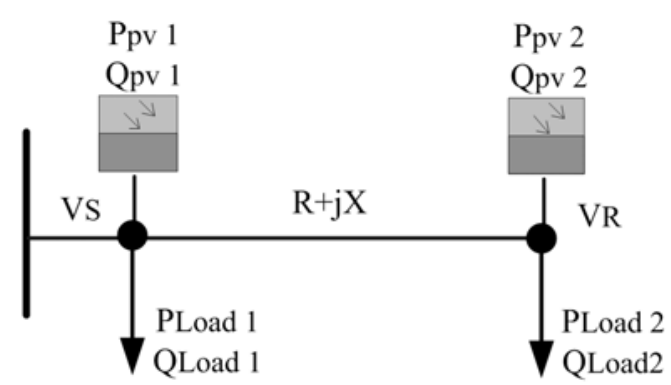

Fig. 1. Network with single node

To understand the impact of PV integration on distribution network voltage at the point of common coupling (PCC), the Thevenin equivalent of inverter generator coupling can be used to derive the voltage change. As seen, the voltage across the load can be derived as:

$$
\Delta V=\frac{R\left(P_{\text {Load }}-P_{p v}\right)+X\left(Q_{\text {Load }} \mp Q_{\text {Load }}\right)}{V_{R}}
$$

Where:

$\Delta \mathrm{V}$ is the difference between sending and receiving side voltages;

$\mathrm{V}_{\mathrm{R}}$ is the receiving side voltage;

$\mathrm{V}_{\mathrm{S}}$ is the sending side voltage;

$\mathrm{R}$ is the line resistance;

$X$ is the line reactance;

$P_{\text {Load }}$ is the load active power;

$Q_{\text {Load }}$ is the load reactive power;

$P_{p v}$ is the inverter active power; and,

$Q_{p v}$ is the inverter reactive power.

It can be seen that the $\left(P_{p v}+j Q_{p v}\right)$ proportionally increases the voltage at the PCC. However, this is valid for just one PCC point. But when there are PV inverters as shown in Fig. 2, the limit of $\Sigma\left(P_{p v}+j Q_{p v}\right)$ is guided by the maximum voltage limit at the last PCC. The limit can be derived by limiting $\Delta V$ to allowable voltage limit. This is shown while developing maximum deviation limit index.

From Fig. 2 it can be seen that for higher PV uptake, the voltage rise is beyond permissible limit, and the voltage rise at each coupling point can be calculated by (2). However, in most of the cases it is very difficult to determine load impedance as it changes continuously throughout the day, and more rapidly for residential loads. But it can be seen that for lower values of $\left(P_{\text {Load }}+j Q_{\text {Load }}\right)$, the maximum permissible value of $\Sigma\left(P_{p v}+j Q_{p v}\right)$ reduces. This means that during off- peak hours, voltage rise due to high PV integration can be severe. This situation can be further aggravated by voltage correction capacitor banks in the system.

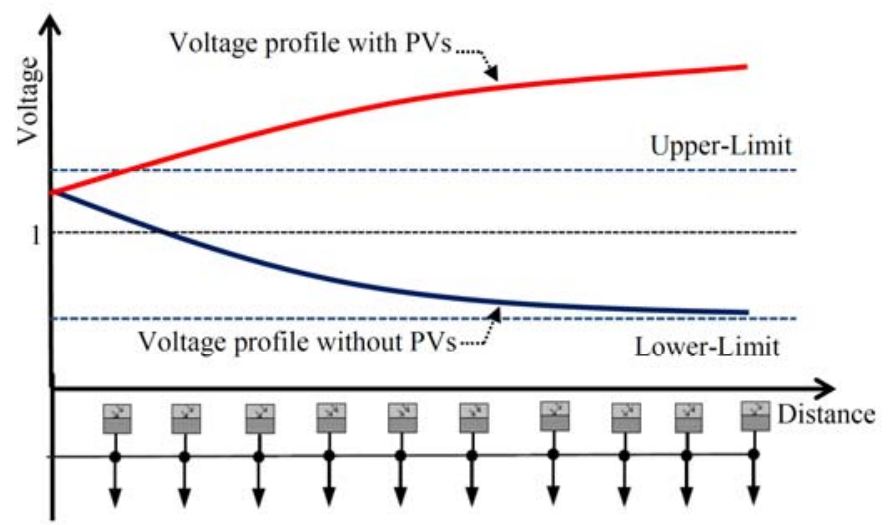

Fig. 2. Voltage Profile with Integration of PV

\section{B. Line Losses}

Distributed generation can contribute to active load and help mitigate the line losses. It must be noted that during heavy load conditions, the reduction in line losses is maximum as demand meets generation and active power flow is reduced. However, the line losses reduce only up to a point where demand supply gap is minimum. During high PV generation and light load conditions, the line losses increase again due to high amount of active power flow. The line losses for single PCC are shown in (3), while for multiple nodes, the sum of all PV generation must be considered by dividing the feeder into different sections, as shown in (4).

$$
\begin{gathered}
\text { Loss }=R I^{2}=R \frac{P_{\text {Load }}^{2}+Q_{\text {Load }}^{2}}{V_{R}^{2}} \\
\text { Loss }=\sum_{i}^{n} R_{i} \frac{\left(P_{\text {Load }_{i}}-P_{p v_{i}}\right)^{2}+\left(Q_{\text {Load }_{i}}-Q_{p v_{i}}\right)^{2}}{V_{R_{i}}^{2}}
\end{gathered}
$$

Where:

$V_{R i}$ is the receiving side voltage at $i^{\text {th }}$ node; $R_{i}$ is the line resistance up till $i^{\text {th }}$ node; $P_{\text {Loadi }}$ is the load active power on $i^{\text {th }}$ node; $Q_{\text {Loadi }}$ is the load reactive power on $i^{\text {th }}$ node; $P_{p v i}$ is the inverter active power on $i^{\text {th }}$ node; $Q_{p v i}$ is the inverter reactive power on $i^{\text {th }}$ node. 


\section{Control modes of inverter}

The reactive power injected or absorbed by the inverters into the grid depends on their operating power factor, which are governed by control mode. The different control modes [10] [12] of the inverters are discussed, namely constant power factor mode or P-Q control mode, voltage control mode and voltage droop control mode. The behavior of the inverter in different modes is explained as follows:

- P-Q control mode- PV inverters usually operate at unity power factor. However they can be set to provide reactive power at a power factor within the range of 0.8 lead to 0.8 lag.

- Voltage control mode- The aim in this control strategy is to try to maintain the voltage at constant value. This is possible by injecting or absorbing reactive power into the system. Suggested value of reactive power generation is up to half of rated active power generation and varies according to the voltage set point.

- Voltage droop control mode- This mode is used to control the node voltage at a set value, however, the set value is never attained as more reactive power is required to reach the set point. Instead a droop value is defined as percentage of set reactive power dispatch of the inverter.

It can be seen that all the modes affect the reactive power produced and fed to the grid by the inverter. If the inverter power factor is set to 1 during constant power factor mode, no reactive power is produced. While reactive power at any other power factor can be calculated. Similarly, in voltage control mode, the power factor and hence reactive power depend on the voltage variation and compensation limit of the inverter. As

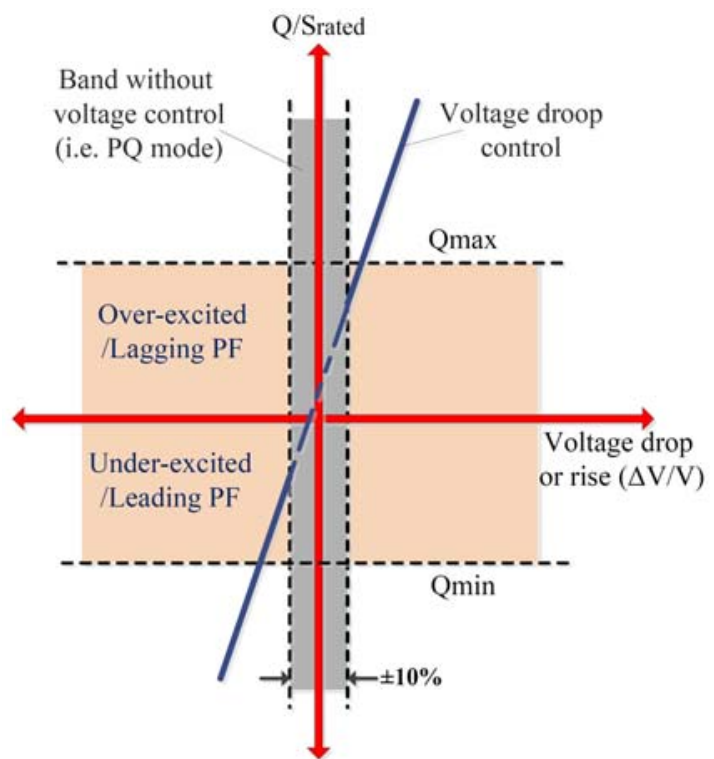

seen from (2) and (4), the voltage deviation and line loss are minimum when the active and reactive power produced by the inverter is equal to the active and reactive load demand. The different operating modes are summarized in Fig. 3.

Fig. 3. Reactive Power against Line Voltage for Control Modes of Inverter
The impacts of PV on distribution network can be realistically modelled with the help of simulation. In this paper, a test network is simulated to understand the behavior of network by analyzing voltage regulation and line losses at each node during operation of inverter in different control modes, operating power factor, and different levels of PV generation.

\section{NETWORK MODEL AND SIMULATION RESULTS}

The network under consideration is shown in Fig. 4. The network consists of 71 Installation Control Points (ICPs) with loads varying between $1 \mathrm{KVA}$ and $3 \mathrm{KVA}$ and $\mathrm{PV}$ generation of $1-3 \mathrm{KW}$. Through a random process, a scaling factor is generated which will be multiplied by the KVA of load as well as PV generation to create a realistic scenario where load and PV generation are uncertain. It must be noted that while the loads are different from each other, they operate at $0.85 \mathrm{pf}$ lagging to account for industrial as well as residential load. The PV generation value once generated through random process is used for all PV inverters as the generation would be same for all PVs in small regional area.

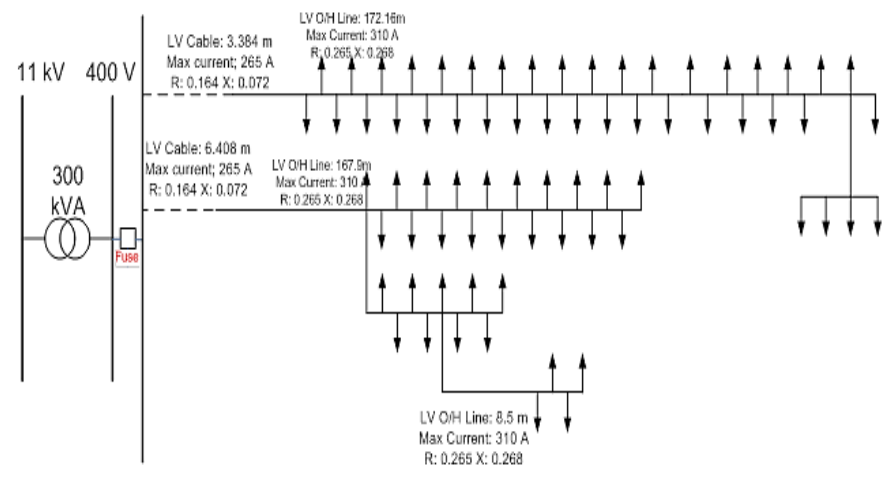

Fig. 4. Network Model

\section{A. Voltage Regulation}

The voltage variation for different penetration of PV with inverter working in PQ Control mode is shown in Fig. 5. However, three different scenarios are created to clearly distinguish the behavior of network under different loading conditions and different power factor of the PV inverter. The three scenarios pertain to different operating mode of PV inverters. It can be seen that during lagging PF operation of the inverter for all three modes, the voltage increases during large PV generation, while best voltage regulation is obtained at unity PF.

Similarly, voltage variations during leading PF operation of the PV inverter are shown in Fig. 5. It was seen that as compared to lagging power factor mode of PV inverter, leading PF mode has better voltage regulation. However, it must be noted that as against lagging PF mode, leading PF mode has least impact on grid when working at lesser PF. The most suited PF were found to be close to unity. It must be noted that as voltage regulation is close to unity during leading PF operation of inverter, it can provide a plausible solution for attaining large PV penetration. The operator has to put a limit to PV penetration to curb voltage rise within allowable range. But when voltage does not rise beyond allowable range, there 
is a scope of increasing PV penetration and fully utilizing the generation capacity.

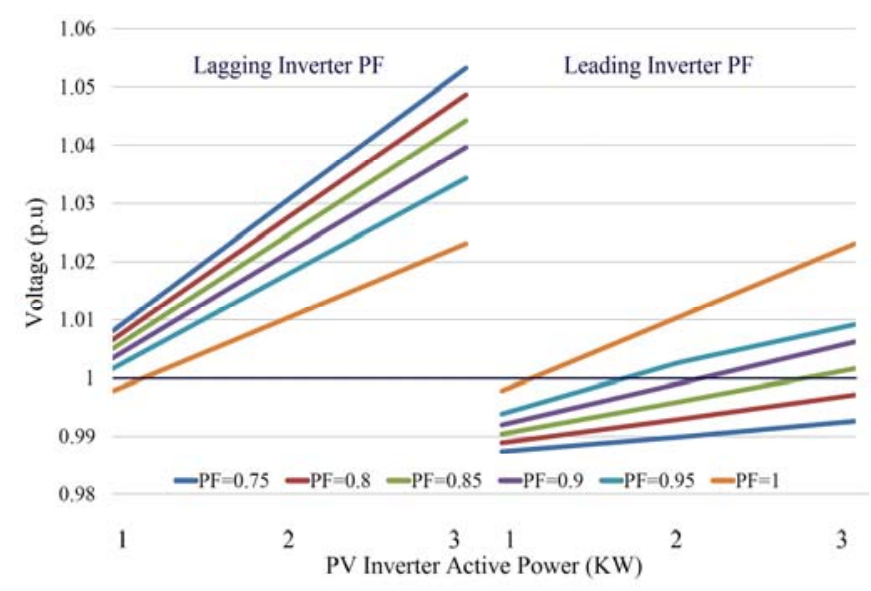

Fig. 5. Voltage Profile with lagging and leading PF of inverter on PQ control mode and $1 \mathrm{~K} \mathrm{~W}$ of load

The voltage profile during voltage droop control mode of inverter operation can be seen in Fig. 6. It can be seen that as compared to PQ control mode, voltage droop control mode has better voltage regulation, especially when the inverter is working in leading power factor region. This is because voltage droop control aims at achieving nominal voltage, but cannot because of the droop factor. For simplicity the voltage profile during operation of PV inverter in voltage control mode is omitted from discussion, as the during voltage control mode the PV inverters actively change their power factor to maintain voltage at $1 \mathrm{Pu}$. Hence, only minute variations are observed.

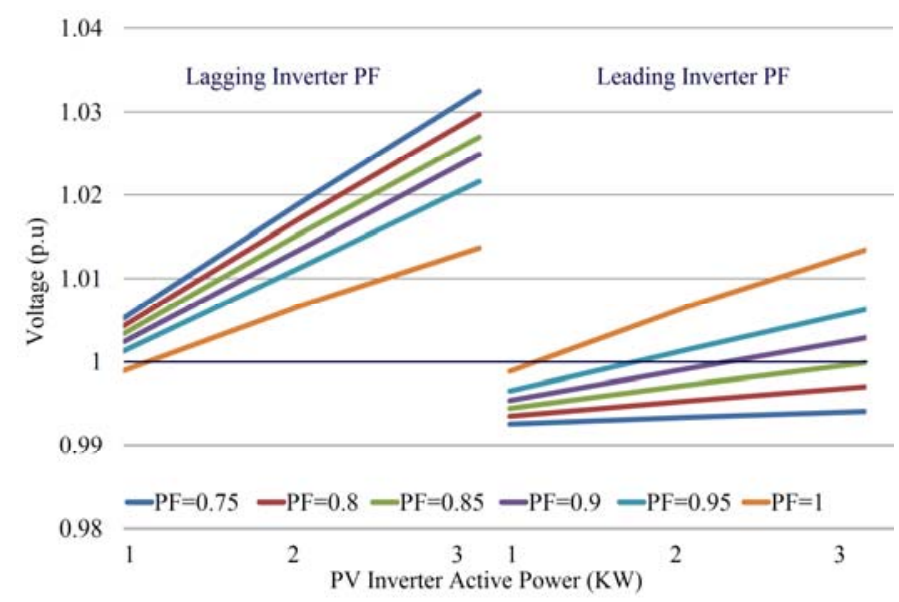

Fig. 6. Voltage Profile with lagging and leading PF of inverter on Voltage droop control mode and $1 \mathrm{~K} \mathrm{~W}$ of load

\section{B. Line Losses}

The line losses are shown in Figs. 7 to 9. It can be seen that distributed generation can mitigate line losses to a great extent. The reduction in line losses are for load of $1 \mathrm{KW}$ and $1 \mathrm{KW}$ of PV generation as 635 watts for all 71 ICPs. However, it must be noted that as subsequently when the load remains same, and PV generation increases, large active power flow again results in increased line losses. Therefore, PV generation must be actively controlled to meet the demand supply gap. Another important thing to note is the drastic increase in line losses in leading PF mode of inverter with reduction in PF. However, it was mentioned before that the impact of leading power factor PV generation is least at lower PF. This leads to a decision making problem, where a compromise has to be made between line losses and voltage regulation. It must be noted that while operating in voltage control mode, the inverter actively changes the reactive power flow to maintain the voltage. This implies that the inverter power factor constantly changes with variation in voltage. Hence power factor is not a factor for evaluating voltage regulation and line losses. This can be seen from Fig. 9; dependence of power factor on line losses cannot be established.

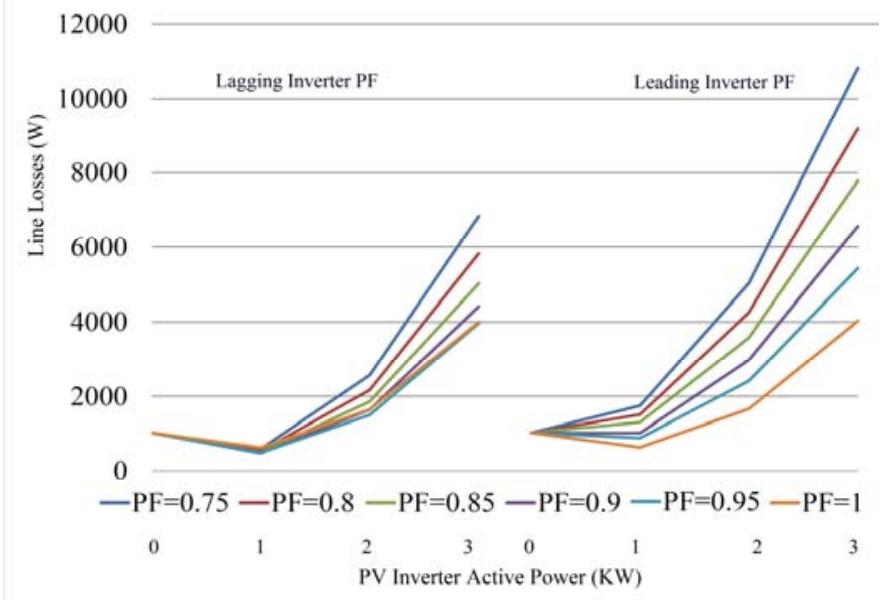

Fig. 7. Line Losses with lagging and leading PF of inverter on PQ control mode and $1 \mathrm{~K} \mathrm{~W}$ of load

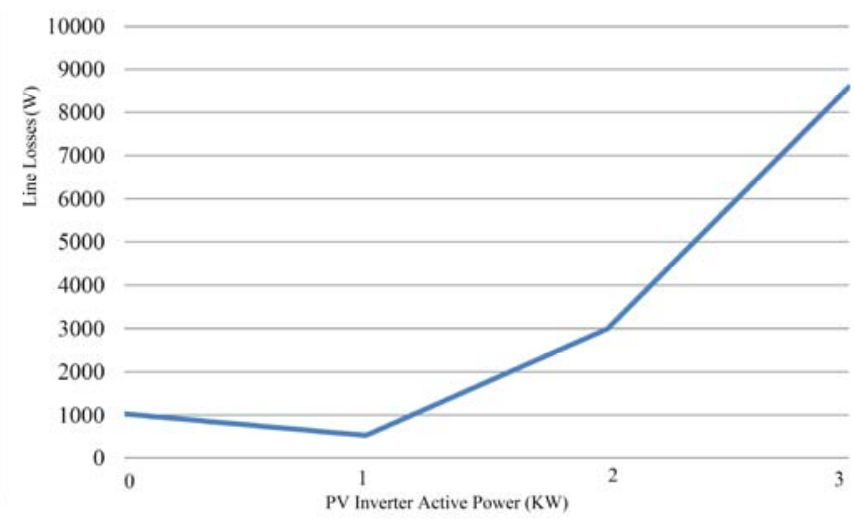

Fig. 8. Line Losses with lagging and leading PF of inverter on Voltage control mode and $1 \mathrm{~K} \mathrm{~W}$ of load

\section{Fault Voltages}

One of the most important aspects of analysis of PV integration is the fault current level as it is expected that it would impact the current protection schemes. Hence to evaluate impacts of PV on fault, an estimate is necessary. The voltage dips at ICPs during a fault are indicators of contribution of PV to fault as voltage dips at some of the ICPs would not be significant if PV generation is high. The voltage profiles during a fault scenario are shown in Fig. 10. 


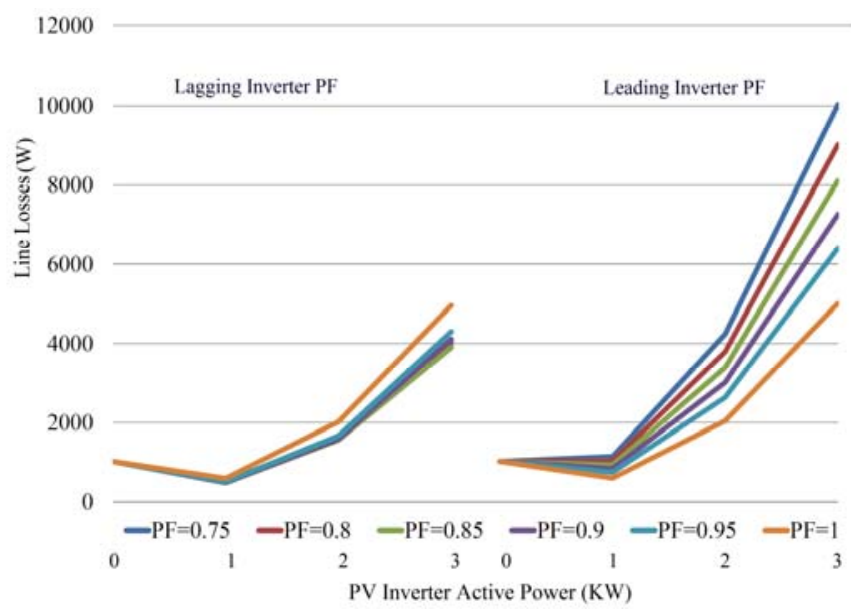

Fig. 9. Line Losses with inverter on Voltage droop control mode and $1 \mathrm{~K} \mathrm{~W}$ of load

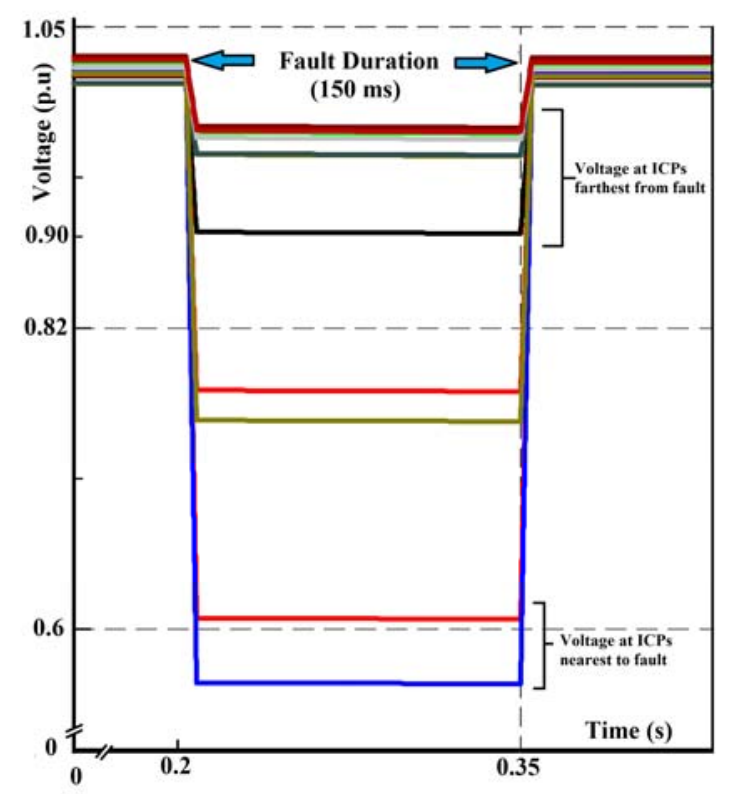

Fig. 10. Voltage at different ICPs during an event of fault

\section{INDEX FOR ANALYSING THE IMPACTS OF PV PENETRATION}

It can be seen that the voltage and line losses are directly related to PV generation and also the mode of operation of the PV inverters. Hence the need of an index to quantify the impacts of PF of inverter and amount of PV generation can be established. To quantify the impact on voltage, we define Maximum Deviation Limit Index, which defined as below:

$$
M D L I=\frac{V_{\text {max }}-V_{t e r \min a l}}{V_{n o \text { min } a l}}
$$

As seen from the (5), $V_{\text {nominal }}$ remains constant and is predefined. Similarly, maximum voltage is defined by the utility. Thus a variation of terminal voltage with respect to maximum possible voltage is obtained as an index of voltage regulation. The variation of MDLI can be seen in Tables I to III. It must be noted that the moment MDLI reaches negative value; the allowed voltage band has been exceeded. Such a scenario can be seen in table I, when the inverter is working in lagging power factor mode and the PV output increases at certain power factor. The effect is most notable for lower power factors. On the other hand, the higher limit of the index can be calculated for the lower voltage limit. For simulation, a maximum allowable voltage deviation of 5\% PU voltage from nominal voltage was used, which sets the limit of the index from 0 to 0.1 . The most desirable point would be at MDLI value of 0.05 . It can be seen from Table II that the value of index is approximately the same for all studied scenarios under constant voltage mode, since all inverters try to maintain the voltage at ICPs at the same level equal to the set value.

TABLE I.

TABLE II. 'MDLI’ DURING PQ CONTROL MODE OF INVERTER

\begin{tabular}{ccccccc}
\hline \multicolumn{7}{c}{ Lagging Inverter PF } \\
\hline PV Output & $\mathrm{PF}=0.75$ & $\mathrm{PF}=0.8$ & $\mathrm{PF}=0.85$ & $\mathrm{PF}=0.9$ & $\mathrm{PF}=0.92$ & $\mathrm{PF}=1$ \\
$\mathrm{PV}=1 \mathrm{~kW}$ & 0.02169 & 0.02325 & 0.02478 & 0.0263 & 0.0282 & 0.03209 \\
$\mathrm{PV}=2 \mathrm{~kW}$ & -0.00119 & 0.001875 & 0.00490 & 0.0080 & 0.0116 & 0.01932 \\
$\mathrm{PV}=3 \mathrm{~kW}$ & -0.0238 & -0.01928 & -0.01472 & -0.0101 & -0.0047 & 0.00658 \\
\hline \multicolumn{7}{c}{ Leading Inverter PF } \\
\hline $\mathrm{PV}=1 \mathrm{~kW}$ & 0.0376 & 0.0360 & 0.03453 & 0.0329 & 0.0311 & 0.02723 \\
$\mathrm{PV}=2 \mathrm{~kW}$ & 0.0351 & 0.0320 & 0.02901 & 0.0258 & 0.0222 & 0.01460 \\
$\mathrm{PV}=3 \mathrm{~kW}$ & 0.0323 & 0.0278 & 0.02331 & 0.0186 & 0.0133 & 0.00198
\end{tabular}

TABLE III. MDLI DURING VOLTAGE CONTROL MODE OF INVERTER

\begin{tabular}{ccccccc}
\hline \multicolumn{7}{c}{ Lagging Inverter PF } \\
\hline PV Output & $\mathrm{PF}=0.75$ & $\mathrm{PF}=0.8$ & $\mathrm{PF}=0.85$ & $\mathrm{PF}=0.9$ & $\mathrm{PF}=0.92$ & $\mathrm{PF}=1$ \\
$\mathrm{PV}=1 \mathrm{~kW}$ & 0.0299 & 0.0299 & 0.0299 & 0.0299 & 0.0299 & 0.0299 \\
$\mathrm{PV}=2 \mathrm{~kW}$ & 0.0299 & 0.0299 & 0.0299 & 0.0299 & 0.0299 & 0.0299 \\
$\mathrm{PV}=3 \mathrm{~kW}$ & 0.0299 & 0.0299 & 0.0299 & 0.0299 & 0.0299 & 0.0299 \\
\hline \multicolumn{7}{c}{ Leading Inverter PF } \\
\hline $\mathrm{PV}=1 \mathrm{~kW}$ & 0.0249 & 0.0249 & 0.0249 & 0.0249 & 0.0249 & 0.0249 \\
$\mathrm{PV}=2 \mathrm{~kW}$ & 0.0249 & 0.0249 & 0.0249 & 0.0249 & 0.0249 & 0.0249 \\
$\mathrm{PV}=3 \mathrm{~kW}$ & 0.0249 & 0.0249 & 0.0249 & 0.0249 & 0.0249 & 0.0249
\end{tabular}

TABLE IV. MDLI DURING VOLTAGE DROOP CONTROL MODE OF INVERTER

\begin{tabular}{ccccccc}
\hline \multicolumn{7}{c}{ Lagging Inverter $\mathrm{PF}$} \\
\hline $\mathrm{PV}$ Output & $\mathrm{PF}=0.75$ & $\mathrm{PF}=0.8$ & $\mathrm{PF}=0.85$ & $\mathrm{PF}=0.9$ & $\mathrm{PF}=0.92$ & $\mathrm{PF}=1$ \\
$\mathrm{PV}=1 \mathrm{~kW}$ & 0.02476 & 0.02571 & 0.02664 & 0.02761 & 0.02872 & 0.03107 \\
$\mathrm{PV}=2 \mathrm{~kW}$ & 0.01083 & 0.01269 & 0.01452 & 0.01643 & 0.01862 & 0.02325 \\
$\mathrm{PV}=3 \mathrm{~kW}$ & -0.00249 & 0.00029 & 0.00305 & 0.00514 & 0.00838 & 0.01634 \\
\hline \multicolumn{7}{c}{ Leading Inverter PF } \\
\hline $\mathrm{PV}=1 \mathrm{~kW}$ & 0.0324 & 0.0315 & 0.0305 & 0.0296 & 0.0285 & 0.0261 \\
$\mathrm{PV}=2 \mathrm{~kW}$ & 0.0316 & 0.0297 & 0.0277 & 0.025 & 0.0235 & 0.0183 \\
$\mathrm{PV}=3 \mathrm{~kW}$ & 0.0309 & 0.0279 & 0.0251 & 0.0221 & 0.0187 & 0.011
\end{tabular}

\section{CONCLUSION}

From the test network simulation, a distinction between various control strategies is made. Usually, most PV inverters currently operate in constant PQ mode with unity power factor operation. In this paper it was shown that voltage regulation can be improved with voltage control mode or voltage droop 
control mode as the inverters in these modes are able to actively control reactive power flow. This can be a potential solution for PV impact mitigation. It must be noted that voltage regulation is best when inverters are operated in leading PF mode. This is generally acceptable as most of the commercial and industrial loads are inductive in nature. However the same cannot be stated for residential loads. The simulation also showed that an enhanced power factor of inverter operated in lagging power factor will improve the voltage regulation. However the described effect is the opposite for leading power factor situations. The line losses show the expected trend as well. A clear relation was seen between $\mathrm{PV}$ penetration/PV power and line losses. Once the local demand is met more active power is delivered by PV, thus increasing the line losses.

The losses are further increased if during leading power factor operation of inverter, the power factor is reduced to improve voltage regulation. Thus an optimum operating point must be found between voltage regulation and line losses. A simple fault analysis was also carried out to show the impact of PV penetration and power on fault current and voltage at respective ICPs.

\section{ACKNOWLEDGMENT}

The authors acknowledge the funding provided by the New Zealand Ministry of Business Innovation and Employment (MBIE) for the GREEN Grid project that has enabled this research to be carried out. The GREEN Grid project is a joint project led by the University of Canterbury with the University of Auckland's Power System Group and the University of Otago's Centre for Sustainability, Food, and Agriculture, and with a number of electricity industry partners. The project, officially titled "Renewable Energy and the Smart Grid" will contribute to a future New Zealand with greater renewable generation and improved energy security through new ways to integrate renewable generation into the electricity network.

\section{REFERENCES}

[1] M. Alam, K. Muttaqi, and D. Sutanto, "An approach for online assessment of rooftop solar pv impacts on low-voltage distribution networks," Sustainable Energy, IEEE Transactions on, vol. 5, no. 2, pp. 663-672, April 2014.

[2] W. Omran, M. Kazerani, and M. Salama, "A clustering-based method for quantifying the effects of large on-grid pv systems," Power Delivery, IEEE Transactions on, vol. 25, no. 4, pp. 2617-2625, Oct 2010.

[3] P. M. S. Carvalho, P. F. Correia, and L. Ferreira, "Distributed reactive power generation control for voltage rise mitigation in distribution networks," Power Systems, IEEE Transactions on, vol. 23, no. 2, pp. 766-772, May 2008.

[4] A. Canova, L. Giaccone, F. Spertino, and M. Tartaglia, "Electrical impact of photovoltaic plant in distributed network," Industry Applications, IEEE Transactions on, vol. 45, no. 1, pp. 341-347, Jan 2009.

[5] V. Quezada, J. Abbad, and T. Roman, "Assessment of energy distribution losses for increasing penetration of distributed generation," Power Systems, IEEE Transactions on, vol. 21, no. 2, pp. 533-540, May 2006.

[6] R. Tonkoski, D. Turcotte, and T. H. M. EL-Fouly, "Impact of high pv penetration on voltage profiles in residential neighborhoods," Sustainable Energy, IEEE Transactions on, vol. 3, no. 3, pp. 518-527, July 2012.

[7] M. Shaaban, Y. Atwa, and E. El-Saadany, "Pevs modeling and impacts mitigation in distribution networks," Power Systems, IEEE Transactions on, vol. 28, no. 2, pp. 1122-1131, May 2013.

[8] K. H. Chua, Y. S. Lim, P. Taylor, S. Morris, and J. Wong, "Energy storage system for mitigating voltage unbalance on low-voltage networks with photovoltaic systems," Power Delivery, IEEE Transactions on, vol. 27, no. 4, pp. 1783-1790, Oct 2012.

[9] H.-G. Yeh, D. Gayme, and S. Low, "Adaptive var control for distribution circuits with photovoltaic generators," Power Systems, IEEE Transactions on, vol. 27, no. 3, pp. 1656-1663, Aug 2012.

[10] E. Demirok, P. Casado Gonzalez, K. Frederiksen, D. Sera, P. Rodriguez, and R. Teodorescu, "Local reactive power control methods for over- voltage prevention of distributed solar inverters in low-voltage grids," Photovoltaics, IEEE Journal of, vol. 1, no. 2, pp. 174-182, Oct 2011 .

[11] X. Su, M. Masoum, and P. Wolfs, "Optimal pv inverter reactive power control and real power curtailment to improve performance of unbalanced four-wire lv distribution networks," Sustainable Energy, IEEE Transactions on, vol. 5, no. 3, pp. 967-977, July 2014.

[12] M. Alam, K. Muttaqi, D. Sutanto, L. Elder, and A. Baitch, "Performance analysis of distribution networks under high penetration of solar pv," Water and Energy International, vol. 70, no. 7, 2013. 